\title{
Integrating Zooarchaeology and Paleoethnobotany: A Consideration of Issues, Methods, and Cases
}

Amber M. VanDerwarker and Tanya M. Peres, eds. 2010. Springer, New York. Pp. 317, 13 color illustrations, 13 black-and-white illustrations. \$129.00 (hardback). ISBN 9781441909343.

\section{Reviewed by Virginia L. Butler}

Reviewer Address: ${ }^{1}$ Department of Anthropology, Portland State University, Oregon 97207

Received: July $20^{\text {th }} 2010$

Published: August $17^{\text {th }} 2010$
Volume 1:20-21

(C) 2010 Society of Ethnobiology
Like the rest of the sciences, archaeology has become increasingly specialized. We've made great strides in sampling, recovery and analysis of various constituents of the archaeological record (bones, plants, lithics, ceramics, dirt, features at various scales). But at the end of the day, results from independent studies of our constituents often are not woven together in comprehensive ways. Where I have worked on the Northwest Coast, varying approaches to sampling classes of faunal remains (shellfish, fish, birds, mammals), which often are collected from different volumes, mesh size, and site context, make it difficult to even compare use of various vertebrates (e.g., fish vs. mammal taxa), much less allow for integrated approaches to faunal and floral analyses. So yes, we need to be working to bring our records together in smart ways to answer important questions about the human past.

This 12-chapter volume edited by Amber VanDerwarker and Tanya Peres is at its base useful, simply for calling attention to the value of explicitly integrating faunal and floral records, particularly for subsistence studies. Part I, comprising the first 4 chapters of the book, lays out the main methodological issues and specific approaches for qualitative and quantitative data integration. Useful and detailed chapters on zooarchaeology (Peres) and paleoethnobotany (Wright) are provided. VanDerwarker outlines simple analytic approaches (e.g., side-by-side comparisons of faunal and floral records using descriptive statistics and correlation analyses) and more complex strategies (Principal Components Analysis [PCA], Correspondence Analysis [CA]) in two chapters. Many good points are emphasized in these introductory chapters: as we attempt to unite disparate records, we need to control for taphonomic differences and depositional contexts of remains; integration is only as good as the independent analyses of each set of data; our questions should focus on change in relative (not absolute) abundances of resource use; and any integrative effort must be guided by the larger research questions and framework of a project.

Part II is comprised of 8 case study chapters that are supposed to show why integrating faunal and floral records is a useful enterprise and how this could be done. These chapters succeed to varying degrees. Peres et al. most closely follow the guidelines set up in Part I, using CA to show differences in plant and animal use by social context at Tres Zapotes, Veracruz, Mexico. They find that plant foods were part of everyday diet and animal foods were linked with higher status and ceremonial contexts. Hollenbach and Walker also use CA to identify trends in Holocene-aged plant and animal records at Dust Cave, Tennessee. Several chapters draw on multiple lines of evidence for inference, but are not focused on integrating faunal and floral records per se. Dickau only reviews plant remains (from Panama). Jones and Quinn consider how to integrate faunal and human bone chemistry data from Fiji (in the context of poor plant preservation). Bartosiewicz et al. review site formation processes affecting plant and animal tissues in shell middens (Scotland); Tóth et al. draw on a range of records (historical, archaeological, ceramic, flora and fauna) to reconstruct diet and environment in Ottoman-era Hungary. Moore et al.'s study of site formation processes affecting plant and animal tissues across a range of feature types in sites by Lake Titicaca, Bolivia, steps back from the specific goal of integration. The authors rightly argue that understanding the cultural and natural processes that account for condition and preservation of bones and plants in a given feature is prerequisite to reconstructing subsistence patterns. Their chapter provides a very useful summary of taphonomic work (their own and that of other scholars) that helps explain patterning in features. 
My next point is less of a complaint and more of an observation: all the authors tend to take a rather post-hoc approach to interpreting patterns rather than begin with a theoretical framework with specific hypotheses that are to be tested. I would argue that a theoretically informed problem orientation -outlining specific goals and expectations -- would greatly assist overall project field design and sampling, which as outlined in Part I, needs to be explicit at a project's inception to facilitate integration of faunal and floral records with all site data. We take it as a given that faunal and floral remains can be used to reconstruct subsistence in descriptive sense (recognizing of course ways that sampling, preservation, and analysis itself can confound our efforts). I suggest we need to be working harder to articulate the larger research questions about how subsistence change and variability can inform us.

I enjoyed and learned much in this book and would recommend it especially for the university library. At $\$ 129.00$, it will exceed the budgets of most students and many professionals. The overall quality of production was good, but at the high cost, I was surprised that several of the maps and figures were blurry or hard to decipher. 